\title{
Erratum to: Effect of chloride concentration and temperature on growth of $1 \mathrm{D}$ pit
}

\author{
Jiheon Jun $^{1}$ • G. S. Frankel ${ }^{1}$ - N. Sridhar ${ }^{2}$
}

Received: 11 May 2016/Accepted: 13 May 2016/Published online: 20 May 2016

(C) Springer-Verlag Berlin Heidelberg 2016

Erratum to: J. Solid State Electrochem. (2015) 19 (12): 3439-3447

DOI 10.1007/s10008-015-2780-4

An error was found in equation 5 that was presented as;

$$
\begin{aligned}
D_{\mathrm{M}+} \cdot C_{\mathrm{M}+}=\frac{i_{\mathrm{lim}} \cdot d}{F} & =2 D_{\mathrm{Fe} 2+} \cdot C_{\mathrm{sat}-\mathrm{Fe} 2+} \\
& +3 D_{\mathrm{Cr} 3+} \cdot C_{\mathrm{Cr} 3+}+2 D_{\mathrm{Ni} 2+} \cdot C_{\mathrm{Ni} 2+}
\end{aligned}
$$

In fact, $D_{\mathrm{M}+} \cdot C_{\mathrm{M}+}$ and $\frac{i_{\text {lim }} \cdot d}{F}$ terms are not equal, and the correct equation should include electric charge ' $n$ ' on the left term as;

$n\left(D_{\mathrm{M}+} \cdot C_{\mathrm{M}+}\right)=\frac{i_{\mathrm{lim}} \cdot d}{F}$

The corrected form of Eqn. 5, then, is written as;

$$
\begin{aligned}
n\left(D_{\mathrm{M}+} \cdot\right. & \left.C_{\mathrm{M}+}\right)=\frac{i_{\text {lim }} \cdot d}{F} \\
& =2 D_{\mathrm{Fe} 2+} \cdot C_{\mathrm{sat}-\mathrm{Fe} 2+} \\
& +3 D_{\mathrm{Cr} 3+} \cdot C_{\mathrm{Cr} 3+}+2 D_{\mathrm{Ni} 2+} \cdot C_{\mathrm{Ni} 2+}
\end{aligned}
$$

The molar ratio of $\mathrm{Fe}, \mathrm{Cr}$ and $\mathrm{Ni}$ in $\mathrm{S} 13 \mathrm{Cr}$ is $81: 14: 5$, and, assuming congruent dissolution, the average value of $n$ is therefore 2.14. The correction of equation 5 will affect equations 6 and 9 as follows.

$$
D_{\mathrm{M}+} \cdot C_{\mathrm{M}+}=C_{\text {sat_Fe2+ }}
$$

$$
2.14\left(D_{\mathrm{M}+} \cdot C_{\mathrm{M}+}\right)=C_{\text {sat_Fe} 2+}
$$$$
\left(2 D_{\mathrm{Fe} 2+}+0.52 D_{\mathrm{Cr} 3+}+0.12 D_{\mathrm{Ni} 2+}\right) \quad[\text { Eqn. } 6, \text { corrected }]
$$$$
D_{\mathrm{M}+} \cdot C_{\mathrm{M}+}\left(\text { at } 85^{\circ} \mathrm{C}\right)=2.64 D_{\mathrm{M}+\_358} \cdot C_{\mathrm{sat}_{-} \mathrm{Fe} 2+} \quad \text { [Eqn. 9] }
$$$$
D_{\mathrm{M}+} \cdot C_{\mathrm{M}+}\left(\text { at }^{\circ} 5^{\circ} \mathrm{C}\right)=1.23 D_{\mathrm{M}+\_358} \cdot C_{\mathrm{sat}_{-} \mathrm{Fe} 2+}
$$

[Eqn. 9, corrected]

Corrected Eqn. 9 decreases the modeled $D_{\mathrm{M}+} \cdot C_{\mathrm{M}+}$ values in Fig. 9:

The online version of the original article can be found at http://dx.doi.org/ 10.1007/s10008-015-2780-4.

G. S. Frankel

frankel.10@osu.edu

1 Fontana Corrosion Center, The Ohio State University,

Columbus, $\mathrm{OH}$, USA

2 DNVGL, Dublin, OH, USA 

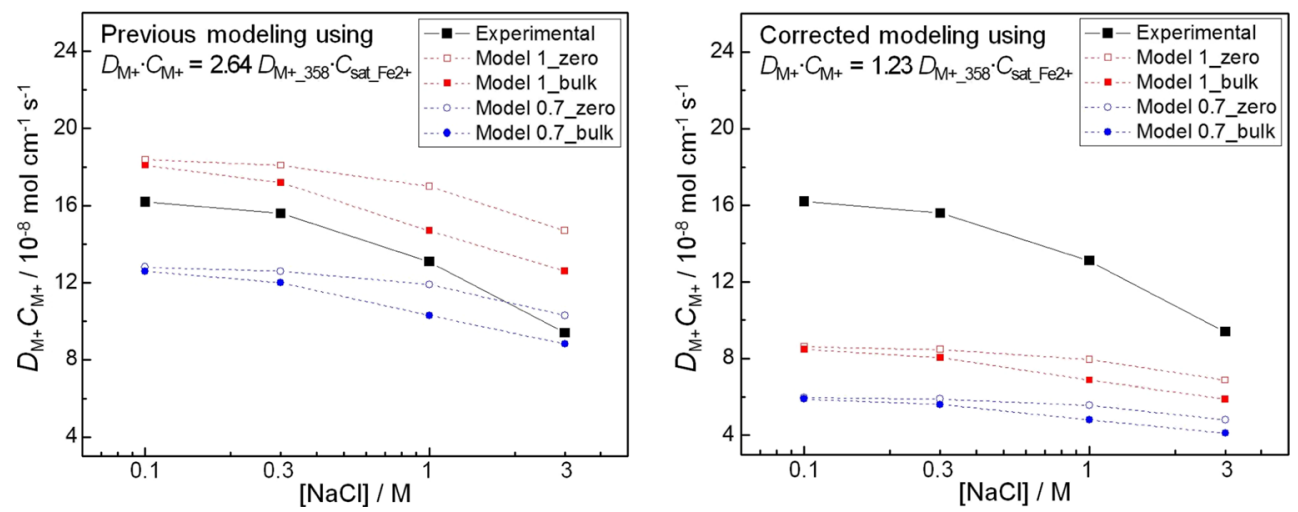

Original (left) and corrected (right) Fig. 9

This issue will be addressed in a separate paper describAfter correction, the calculated values of $D_{\mathrm{M}+} C_{\mathrm{M}+}$ were smaller than the experimental data in all $\mathrm{NaCl}$ concentrations, implying the modeled $D_{\mathrm{M}+}$ and/or $C_{\text {sat }}$ could be underestimated. ing the re-analysis of the modeled $D_{\mathrm{M}+}$ and $C_{\text {sat }}$ for better fitting between experimental and modeled values of $D_{\mathrm{M}+} C_{\mathrm{M}+}$. 